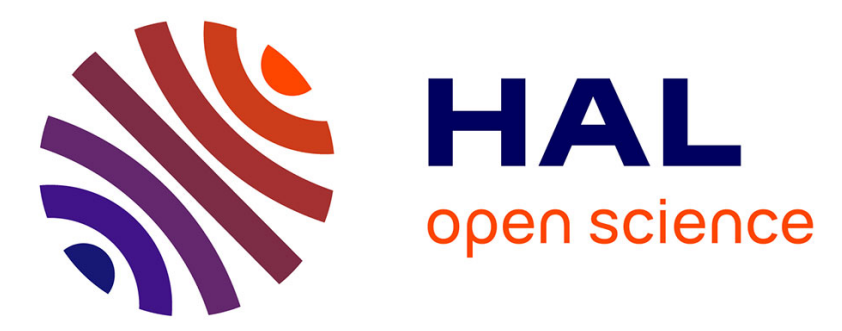

\title{
Nuclear power: a promising back-up option to promote renewable penetration in the French power system? Topic: Renewable system integration
}

Camille Cany, Christine Mansilla, Pascal da Costa, Gilles Mathonnière, Jean Baptiste Thomas

\section{To cite this version:}

Camille Cany, Christine Mansilla, Pascal da Costa, Gilles Mathonnière, Jean Baptiste Thomas. Nuclear power: a promising back-up option to promote renewable penetration in the French power system? Topic: Renewable system integration. World Renewable Energy Congress (WREC XIII), Aug 2014, London, United Kingdom. pp.69-80, 10.1007/978-3-319-18215-5_7 . hal-01264244

\section{HAL Id: hal-01264244 \\ https://hal.science/hal-01264244}

Submitted on 29 Jan 2016

HAL is a multi-disciplinary open access archive for the deposit and dissemination of scientific research documents, whether they are published or not. The documents may come from teaching and research institutions in France or abroad, or from public or private research centers.
L'archive ouverte pluridisciplinaire HAL, est destinée au dépôt et à la diffusion de documents scientifiques de niveau recherche, publiés ou non, émanant des établissements d'enseignement et de recherche français ou étrangers, des laboratoires publics ou privés. 
World Renewable Energy Congress - WREC XIII, 3-8 August 2014, University of Kingston, London, UK

\title{
Nuclear power: a promising back-up option to promote renewable penetration in the French power system?
}

\author{
Camille Cany, CEA DEN I-tésé and ECP LGI, \\ CEA Saclay 91191 Gif-sur-Yvette Cedex France, camille.cany@cea.fr \\ Christine Mansilla, CEA DEN I-tésé, \\ CEA Saclay 91191 Gif-sur-Yvette Cedex France, christine.mansilla@cea.fr \\ Pascal Da Costa, ECP LGI, \\ Ecole Centrale de Paris, Laboratoire de Génie Industriel, Grande Voie des Vignes, F-92 295 Châtenay Malabry Cedex France, pascal.da- \\ costa@ecp.fr \\ Gilles Mathonnière, CEA DEN I-tésé, \\ CEA Saclay 91191 Gif-sur-Yvette Cedex France, gilles.mathonnière@cea.fr \\ Jean-Baptiste Thomas, CEA DEN DIR EC, \\ CEA Saclay 91191 Gif-sur-Yvette Cedex France, jean-baptiste.thomas@cea.fr
}

Topic: Renewable system integration

Keywords: renewable energy penetration; non-dispatchable renewable sources; back-up; low-carbon sources synergy

\begin{abstract}
:
The general 3X20 European directive proposes renewable penetration goals. In France, $27 \%$ of the electricity is to be produced by renewable resources by 2020 and this share will be continuously growing up to 2050 . Among these resources, some -like wind and solar- are not dispatchable, which triggers challenges to maintain the reliability target level of the power system, both in the short and long term. Wind and solar are expected to contribute to about $12 \%$ of the French electricity production in 2020 and according to voluntaristic scenarios they could contribute to over $50 \%$ of the total electricity production by 2050.

The increase of the non-dispatchable renewable share in the power system modifies the residual demand (which is equal to the demand minus non-dispatchable renewable production) pattern to more power ramping and higher variation amplitudes. To keep the system balanced, back-up options are numerous, though scarcely considered exhaustively in power systems modelling. Besides peaking unit production -such as gas turbines- which is usually the preferred option, storage, demand (or supply) curtailment, interconnections and baseload (nuclear for instance) power modulation should also be considered, particularly in such a context of high non-dispatchable renewable penetration.

In a French context of significant production of nuclear power, nuclear modulation is investigated as a feasible opportunity to facilitate renewable energy penetration. Available capacity is assessed based on realistic scenarios and through the use of residual load duration curves. The load modulation impact on the nuclear levelized cost of electricity is estimated, and nuclear back-up option is compared to gas on economic and environmental terms. Gas back-up is more competitive

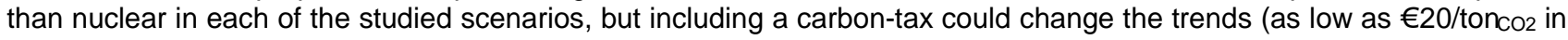
some cases). This advocates for such incentives to avoid the effective greenhouse gas release. Nuclear back-up would be all the more competitive than power plants used are amortized.
\end{abstract}

\section{Introduction}

The 3X20 European directive proposes renewable penetration goals [1]. In France, $27 \%$ of the electricity is to be produced by renewable resources (RES) by 2020 [2] and this share will be continuously growing up to 2050. Among these resources, some -like wind and solar- are not dispatchable, which triggers challenges to maintain the reliability target level of the power system, both in the short and long term [3], [4].

Non-dispatchable renewable resources currently benefit from a dispatch priority. The increase of their share in the power system modifies the residual demand (which is equal to the demand minus non-dispatchable renewable production) pattern to more power ramping and higher variation amplitudes. To keep the system balanced, back-up options are numerous, though scarcely considered exhaustively in power systems modelling (e.g. [5], [6]). Besides peaking unit production -such as gas turbines- which is usually the preferred option, storage, demand (or supply) curtailment, interconnections and baseload (nuclear for instance) power modulation should also be considered, particularly in such a context of high non-dispatchable renewable penetration [7].

Considering the French power system, in order to maintain its reliability target level, nuclear power could participate to system balancing thanks to characteristics compatible with power modulation [8]-[11]. Increasing non-dispatchable renewable penetration levels would entail higher balancing needs [12], hence lesser outputs and operational modifications for nuclear power (e.g. higher fuel use, more maintenance needs, increased material and components ageing) [9].

This paper investigates the overall economic impact of such an operating mode and compares nuclear and gas power load following options up to 2050, based on production costs and CO2 emission criteria. Several non-dispatchable renewable penetration level scenarios have been developed for France that take into account both wind and solar whereas most studies only focus on wind and hardly ever consider nuclear (e.g. [3], [5]). These scenarios are first detailed (section II). Then the methodology is presented (section III), followed by the results and discussion (section IV).

\section{Power system scenarios}


World Renewable Energy Congress - WREC XIII, 3-8 August 2014, University of Kingston, London, UK

In 2013, the French Government launched a broad national consultation on the energy transition [13]. In this framework, several institutions designed energy prospective scenarios for France.

The Institute for techno-economics of energy systems of the Commissariat à l'Energie Atomique et aux Energies Alternatives (CEA/I-tésé) was involved in the contribution of the ANCRE (Alliance Nationale de Coordination de la Recherche pour l'Energie, the French National Alliance for Energy Research Coordination), that proposed three contrasted scenarios that all satisfy the factor 4, i.e. a reduction by four of the greenhouse gas emissions in 2050 , compared to the 1990 level [14]. The specificity of these scenarios is a voluntaristic approach in terms of scientific and technological innovation. All these scenarios propose a similar non-dispatchable renewable penetration for a given time horizon, leading to a maximum energy penetration of $30 \%$ by 2050 (wind and solar). As regards nuclear power, two cases are considered: a $50 \%$ value (of the annual electricity production), in line with the French Government policy, and a "high nuclear" case with a $65 \%$ value.

In order to consider a more voluntaristic scenario in terms of non-dispatchable renewable penetration, we also considered the scenario proposed by the ADEME (Agence de l'Environnement et de la Maîtrise de l'Energie, the French Environment and Energy Management Agency), which examines the case of $50 \%$ non-dispatchable renewable penetration by 2050 [15]. The ADEME also considered lower nuclear penetration (down to $20 \%$ ).

Furthermore, as regards nuclear power contribution to the French electricity mix, we also considered a "business-as-usual" value of $75 \%$, which corresponds to the nuclear current contribution to the French annual electricity production [16].

Finally, we established generic scenarios by crossing the renewable and nuclear penetration assumptions (cf. Table I and Table II), and studied each of them. For readability issues, only three contrasted cases will be presented in the results and discussion section. They provide conceivable target capacities in line with the current energy policy as regards RES development and the specific French context characterized by the significant place of nuclear power in the power mix:

1. "median scenario" (med): $16.5 \%$ wind and solar in 2030, 30\% in 2050, 50\% nuclear in both cases;

2. "high nuclear scenario" (high nuc): $65 \%$ nuclear, wind and solar shares as in the median case;

3. "high non-dispatchable renewable scenario" (high ren): $30 \%$ wind and solar in $2030,50 \%$ in $2050,50 \%$ nuclear in both cases.

TABLE I.

RENEWABLE ENERGY PENETRATION SCENARIOS

\begin{tabular}{|c|c|c|c|c|}
\hline Time horizon & Wind penetration & Solar penetration & Total (\%) & Reference scenario \\
\hline 2015 & $5 \%$ & $1 \%$ & $6 \%$ & ANCRE [14] \\
\hline 2020 & $8 \%$ & $2 \%$ & $10 \%$ & ANCRE [14] \\
\hline 2025 & $10 \%$ & $3 \%$ & $13 \%$ & ANCRE [14] \\
\hline 2030 & $12 \%$ & $4.5 \%$ & $16.5 \%$ & ANCRE [14] \\
\hline 2040 & $16 \%$ & $7 \%$ & $23 \%$ & ANCRE [14] \\
\hline 2050 & $20 \%$ & $10 \%$ & $30 \%$ & ANCRE [14] \\
\hline 2050 & $30 \%$ & $15 \%$ & $45 \%$ & ADEME [15] \\
\hline 2050 & $35 \%$ & $15 \%$ & $50 \%$ & ADEME [15] \\
\hline
\end{tabular}

TABLE II.

NUCLEAR ENERGY SCENARIOS

\begin{tabular}{|c|c|}
\hline Nuclear penetration & Reference scenario \\
\hline $75 \%$ & Business-as-usual \\
\hline $65 \%$ & High nuclear in ANCRE [14] \\
\hline $50 \%$ & Low nuclear in ANCRE [14] or High \\
nuclear in ADEME [15]
\end{tabular}

In order to assess the economic impact of nuclear power modulation operation, two scenarios have been defined as regards the French operational nuclear fleet (Pressurized Water Reactors (PWR) and Evolutionary Power Reactors $\left(\mathrm{EPR}^{\mathrm{TM}}\right)$ capacity evolution is shown on Fig. 1):

- Current reactors are operated 40 years and then shut down ("40 yrs" scenario);

- The current fleet is progressively replaced to avoid massive investment in a short period of time: 2 GWe are shut down each year ("prog."; it is the "best-estimate" scenario).

In each case, the current fleet is completed by $\mathrm{EPR}^{\mathrm{TM}}$ in order to achieve the target nuclear penetration level of the selected scenario (cf. Fig. 1). 
World Renewable Energy Congress - WREC XIII, 3-8 August 2014, University of Kingston, London, UK

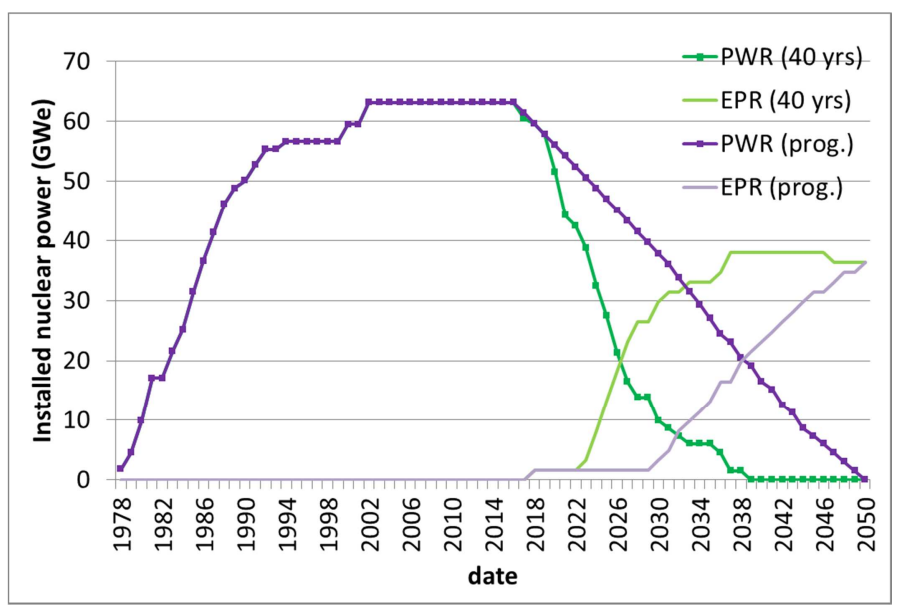

Figure 1. PWR \& EPR ${ }^{\mathrm{TM}}$ capacity evolution scenarios (for $50 \%$ nuclear penetration), own calculus

These scenarios have been established based on realistic expectations (the operating life extension of nuclear power plants is currently discussed in France) [17] and will result in different production costs according to the composition of the nuclear mix (the Capex of the nuclear mix is computed from the share between amortized power plants (PWR) and recently installed ones (EPR ${ }^{\mathrm{TM}}$ ). Opex and life extension costs have also been included. They are issued from the French Court of Auditors in-depth study of the nuclear costs in the French context [24]).

\section{Methodology: an approach based on the construction of annual residual load duration curves}

To assess the impacts of non-dispatchable renewable resources on other power plants capacity requirements and annual productions in a power system, two major types of approaches can be distinguished. First, the construction of load net of wind and solar (called "residual" in what follows) duration curves for different wind and solar penetration levels allows determining the optimal mix of other generation resources in the long term [5], [6], [18]. Secondly, a minimum cost economic dispatch model can serve refining the general trends obtained from the first approach [5], [6], [19], [20]. The use of such a time step model allows short term supply and demand balancing in response to technical, economic and political constraints. We focus here on the first approach to put a light on general trends in the long term.

The developed methodology proceeds in several steps. On the one hand, the construction of annual residual load duration curves allows assessing the annual energy productions and optimal installed capacities, among which the needs for baseload installed power that will be fulfilled by nuclear in the French case. On the other hand, nuclear cycling capacity is evaluated based on the realistic French nuclear fleet scenarios that were presented in the previous section. Thanks to the annual residual load duration curves, we evaluate and compare nuclear fleet effective full power hours of both options: nuclear power fleet operated as a baseload capacity or as a combined option: baseload and cycling capacity. We then carry out the economic comparison. Finally, through the same approach, the nuclear load following option is compared to the gas one, which is considered as the reference back-up option.

\subsection{Construction of annual residual load duration curves}

A load duration curve represents the sorted hourly load of one year, starting with the highest load hour. The residual load curve is obtained by withdrawing the wind and solar production to the total annual production (considered constant on an annual cumulated basis in this study, hourly variations have been computed into the residual load duration curve based on the historical data from the French Transmission System Operator (RTE)). Wind and solar production was estimated by calculating mean hourly power values of historical data (between 2010 and 2013) also from RTE [21], and by calibrating their hourly power to fit their assumed energy penetration level to satisfy a given demand (cf. Table I). The resulting curves are displayed on Fig. 2. 
World Renewable Energy Congress - WREC XIII, 3-8 August 2014, University of Kingston, London, UK

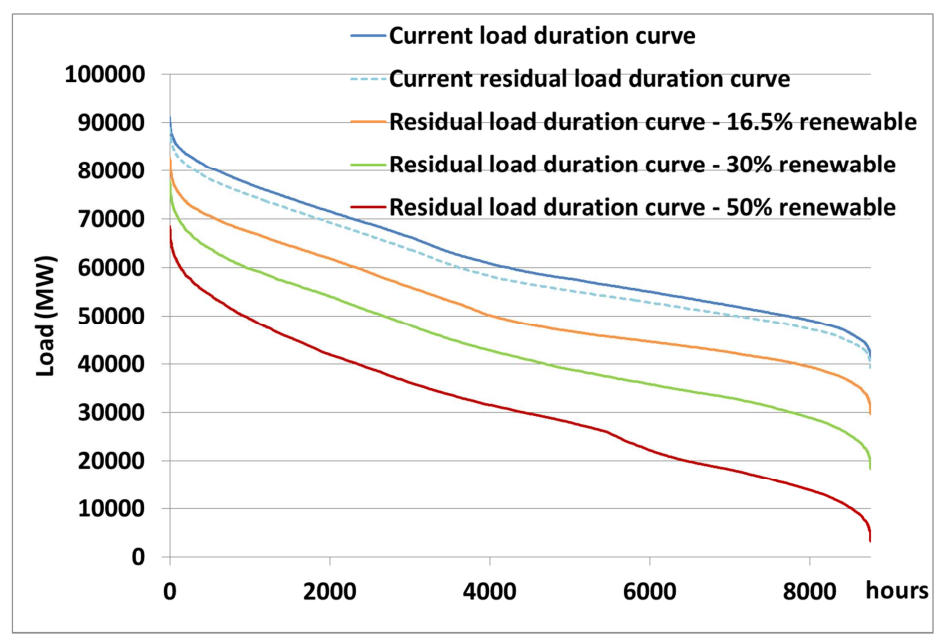

Figure 2. Residual load duration curves, own calculus

\subsection{Assessment of the "optimal" nuclear power generation and the nuclear cycling capacity}

The construction of screening curves (cf. Fig. 3) allows estimating the lowest total cost technology for a given operating time. Thus, they provide the optimal annual operating time for each resource type (e.g. 7900 hours for nuclear on the example given by Fig. 3), which can then be copied on the residual load duration curve, to assess the corresponding optimal installed power.

Baseload installed power will be fulfilled by nuclear in the French case. Other unavoidable energy productions capacities have been taken into account nonetheless (e.g. run-of-river hydroelectric plant).

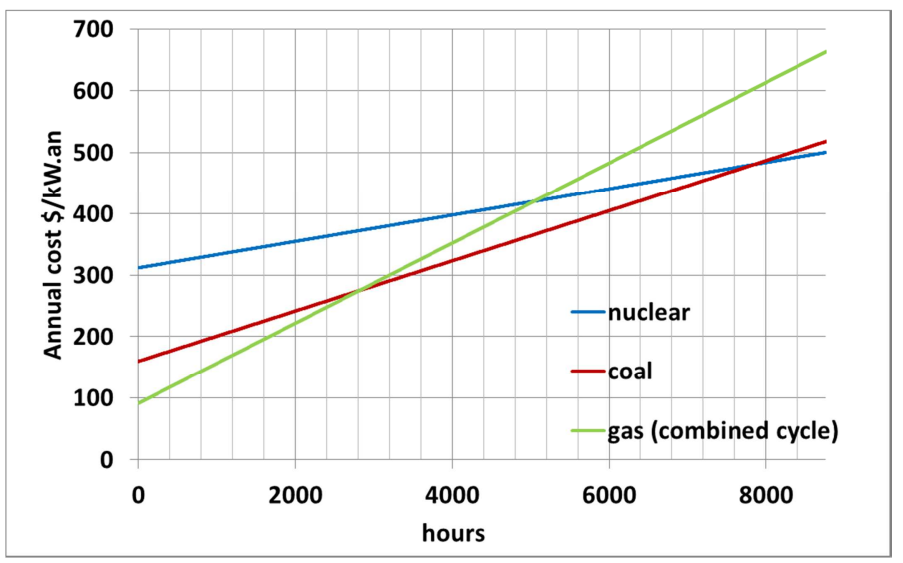

Figure 3. Screening curve example (cost data from [22], 8\% discount rate, no carbon price), own calculus

While screening curves are commonly used to establish the optimal electric mix, our analysis showed that the results are extremely sensitive to the assumptions in terms of investment costs (are the interests during construction taken into account? What is the discount rate?), and $\mathrm{CO} 2$ price, only to name a few. When considering nuclear investment (very capex-intensive and low-carbon), these assumptions are critical. According to our calculations, when varying the discount rate of 3 points, or when taking into account a carbon price of $\$ 30 /$ tonCO2, the optimal operating time of nuclear power could vary between 3000 and 8000 hours, leading to a resulting installed capacity between 55 GW and 40 GW, for $16.5 \%$ renewable penetration for instance.

Given this uncertainty range, we retained an empirical approach based on the historical availability factor of nuclear in France (return on operating experience) [23]. The selected value is 7000 hours. Such an approach rather minimizes the resulting installed nuclear capacity. The optimal nuclear power will be derived by confronting this economical operating duration to the residual load curve that was constructed as explained in the previous section. By comparing the optimal nuclear power that corresponds to a given total annual production and non-dispatchable renewable energy penetration, to the installed power provided by the selected scenario, the available cycling power is assessed (cf. Fig. 4). 
World Renewable Energy Congress - WREC XIII, 3-8 August 2014, University of Kingston, London, UK

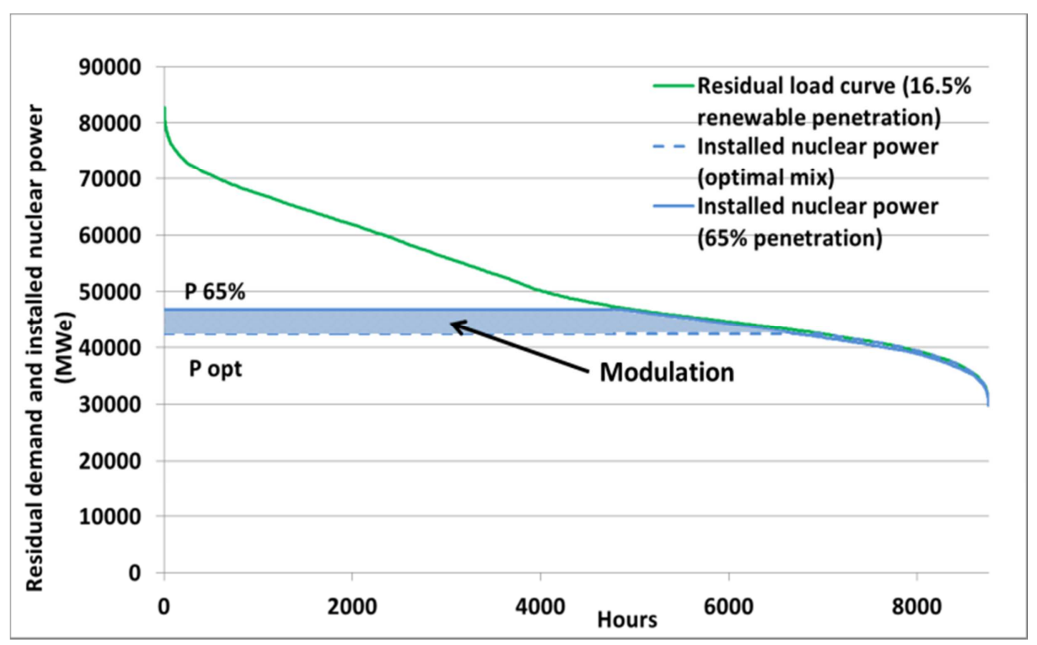

Figure 4. Example of assessment of the nuclear power modulation capacity ("high nuc" 2030), own calculus

\subsection{Assessment of the economic and environmental impacts}

The economic impact can be assessed from two viewpoints:

- $\quad$ From the power plant operator viewpoint: the power plant does not supply all the available energy (cf. Fig. 4) and cycling operation induces overcosts (to be included in future studies). This will be assessed by comparing the levelized cost of electricity (LCOE, [22]) of the installed nuclear power either operated as a baseload or as a cycling capacity as imposed by the residual load (as shown in Fig. 4);

- $\quad$ From the social welfare viewpoint: if not provided by nuclear, load following would have been carried out by other means. In this study we chose to compare to the gas power plant reference. The comparison is done by confronting the total cost of supplying the "cycling power" part (in blue in Fig. 4) either by nuclear or by gas. In the latter case, $\mathrm{CO} 2$ emissions will also be assessed and internalized in the electricity cost.

Cost assumptions as regards nuclear plants are issued from the French Court of Auditors [24] while the OECD assumptions have been adapted to the French case for the gas-fired power plants [22]. The open cycle gas turbine (OCGT) was selected as the reference due to its cycling abilities.

\section{Results and discussion: The impact of renewable penetration on nuclear power generation - cost and environmental issues}

As explained in the previous section, the installed nuclear power was confronted to the "optimal" value for each scenario, in order to assess the cycling possibility.

Firstly, scenarios are compared through the corresponding optimal installed nuclear power. Table III shows the share of the total electricity production that would be provided by nuclear (for an economically optimal mix), according to the renewable penetration. From this table, we can point out that, for $16.5 \%$ renewable penetration, $57 \%$ of the electricity should be supplied by nuclear in the optimal case. Hence, $50 \%$ nuclear penetration (corresponding to the "med" scenario in 2030), is sub-optimal: no nuclear cycling capacity is available.

TABLE III. NUCLEAR CONTRIBUTION TO SATISFY THE TOTAL ELECTRICITY PRODUCTION IF THE OPTIMAL MIX WAS IMPLEMENTED, ACCORDING TO THE RENEWABLE PENETRATION

\begin{tabular}{|c|c|}
\hline Renewable penetration (\%) & Nuclear penetration (\%) \\
\hline 16.5 & 57 \\
\hline 30 & 41 \\
\hline 50 & 17 \\
\hline
\end{tabular}

Concerning the nuclear production cost, the two scenarios of nuclear fleet composition are compared in Fig. 5 ("prog" and "40 yrs"). Implementing a progressive shut-down first enables making profit from amortized PWRs (cycling is even less expensive than baseload operation from 2030 to 2050). It remains less expensive than the "40 yrs" scenario, even once amortized PWRs have been shut down. Indeed EPRs ${ }^{\text {TM }}$ that are installed later are characterized by higher availability, which results in smaller installed capacity needs, hence a reduced investment. 
World Renewable Energy Congress - WREC XIII, 3-8 August 2014, University of Kingston, London, UK

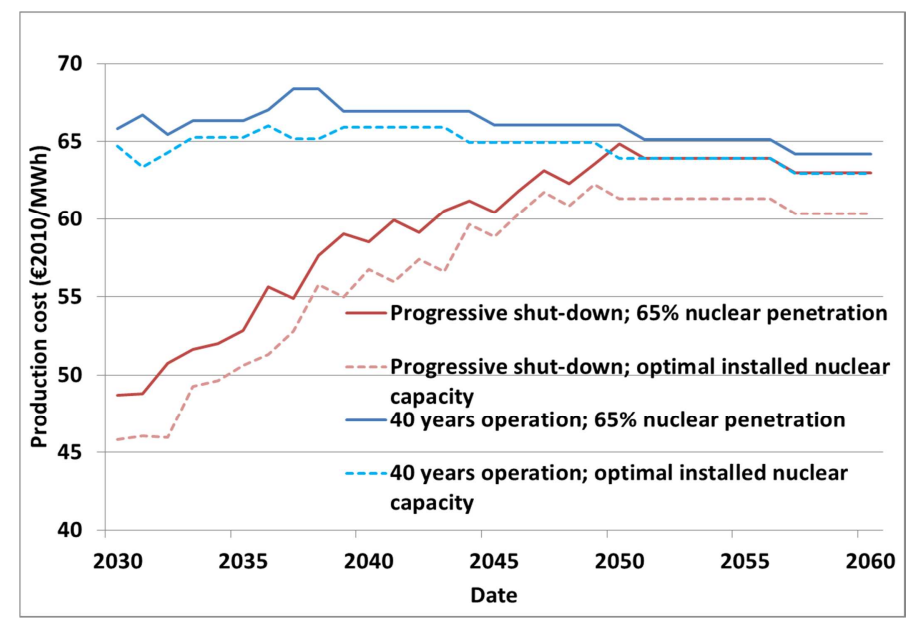

Figure 5. Nuclear production cost according to the nuclear fleet composition scenario ("40 yrs" or "prog"), own calculus

Since the "prog" scenario corresponds to the more realistic one in the French context, we will focus on it. For a given nuclear penetration level, the share of nuclear energy which is devoted to modulation increases more than linearly with the renewable penetration level. It is worth noticing that for the "high ren" scenario in $2050,50 \%$ of nuclear energy would be dedicated to modulation. Fig. 6 shows the impact of modulation (loss of load factor) on the nuclear LCOE. The impact of the nuclear fleet composition on nuclear LCOE is pointed out by comparing the "med" 2050 case to the "high ren" 2030 case: similar nuclear and renewable penetration levels end up in different relative extra production costs. Indeed, in 2050 , nuclear fleets are only composed of EPR ${ }^{\mathrm{TM}}$ whatever the renewable penetration scenario, while in 2030, relative costs are strongly dependent on the PWR replacement rate according to nuclear energy penetration targets.

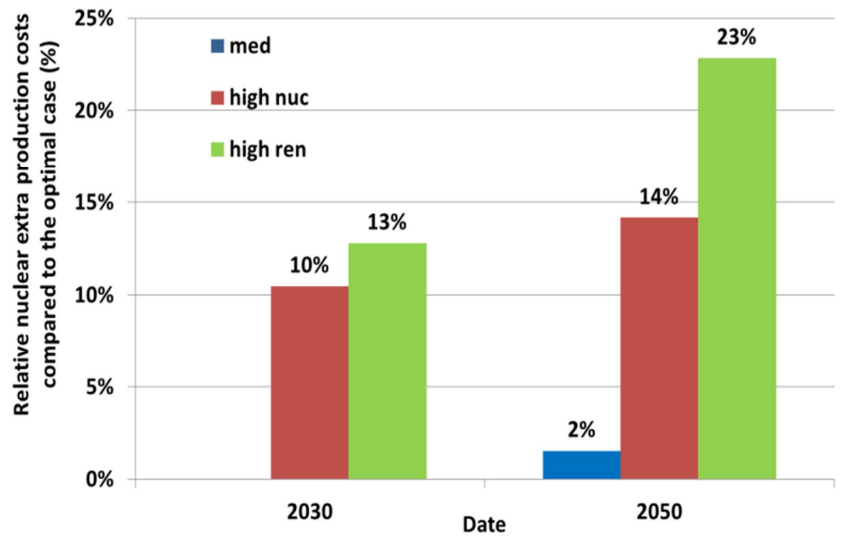

Figure 6. Load modulation impact on the nuclear LCOE, own calculus

Finally, results show that the gas cycling option is cheaper than nuclear back-up in each scenario. For a given $\mathrm{CO}_{2}$ price value, the gas price which leads to equalize the cost of both options is determined. Conversely, the same approach is followed for a given gas price value. For all the scenarios the results are in the same order of magnitude: $\mathrm{i} /$ for a $\mathrm{CO}_{2}$ price of $€ 5 /$ ton $_{\mathrm{CO} 2}$ (which corresponds to the current market value [25]), nuclear back-up is competitive when the gas price exceeds $€ 35 / \mathrm{MWh}$; ii/ for a gas price of €31/MWh (which corresponds to the ANCRE assumption for 2030 [14]), the gas

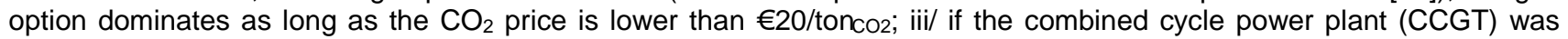
considered as the gas option (less flexible, yet probably enough), the previous results would be modified to $€ 50 / \mathrm{MWh}$ and $€ 110 /$ ton $_{\text {co2 }}$ respectively.

Overall, the gas option, even when cheaper would generate $\mathrm{CO}_{2}$ emissions in the range of 10-50Mt per year, depending on the scenario and the time horizon.

\section{Conclusion and perspectives}

Nuclear modulation seems to be achievable, especially in the case of France since a large production variation could be reached only by small increments in each power plant. This would remain true as long as installed nuclear power is large enough, in terms of contribution to the global electricity mix.

In economic terms, gas back-up is more competitive than nuclear in each of the studied scenarios. However a carbon-tax

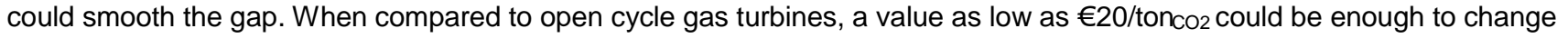


World Renewable Energy Congress - WREC XIII, 3-8 August 2014, University of Kingston, London, UK

the trends, which advocates for such incentives to avoid the effective greenhouse gas release. Nuclear back-up is all the more competitive than amortized power plants are utilized.

Further studies could focus on assessing the impact of an increasing electricity demand, or technological progress by also including the overcosts due to cycling operation (both for the nuclear and gas options). When increasing the nondispatchable energy penetration, other back-up options, such as storage, curtailment, or demand-side management tools, should be considered as contributors to the "back-up" mix whose optimum remains to be established. This could be done through the use of a minimum cost economic dispatch model.

Finally, nuclear modulation was apprehended via the concept of load following. Another way to reach the same target could be modulating through the output. In this case, the nuclear power plant would be operated as a baseload and electricity would be supplied to the electric system when requested. For the remaining time, instead of reducing the plant load, the output could be used to produce other valuable products such as heat or hydrogen [26]. The competitiveness of these productions is still to be proven and will be the topic of future works.

\section{Acknowledgment}

This work was carried out in the framework of a $\mathrm{PhD}$ thesis. The authors want to thank J. C. Bocquet, Head of the Laboratoire de Génie Industriel, and J. G. Devezeaux, Head of the Institute for techno-economics of energy systems (I-tésé) for the fruitful discussions.

\section{References}

[1] European Directive 2009/28/CE, 23 Apr. 2009.

[2] Ministère de l'Ecologie, de l'Energie, du Développement Durable et de la Mer, "Plan d'action national en faveur des énergies renouvelables. Période 2009-2020. En application de l'article 4 de la Directive 2009/28/CE de l'Union Européenne", 2009.

[3] R. Gross, P. Heptonstall, D. Anderson, T. Green, M. Leach et al., "The costs and impacts of intermittency: an assessment of the evidence on the costs and impacts of intermittent generation on the British electricity network", UK Energy Research Centre, London, UK, Mar. 2006.

[4] E. Hart, E. D. Stoutenburg, and M. Z. Jacobson, "The potential of intermittent renewables to meet electric power demand: current methods and emerging analytical techniques", Proceedings of the IEEE, 100(2), pp. 322-334, Feb. 2012.

[5] C. D. Davis, D. J. Gotham, P. V. Preckel, and A. L. Liu, "Determining the impact of wind on system costs via the temporal patterns of load and wind generation", Energ Policy, vol. 60, pp. 122-131, Sep. 2013.

[6] J. H. Keppler, M. Cometto, "Nuclear energy and renewables: system effects in low-carbon electricity systems", Nuclear Energy Agency, OECD, Paris, France, 2012.

[7] M. M. Hand, S. Baldwin, E. DeMeo, J. M. Reilly, T. Mai, et al., "Renewable electricity futures study, vol.1: Exploration of high-penetration renewable electricity futures", National Renewable Energy Laboratory, Golden, CO, NREL/TP6A20-52409-1, 2012.

[8] C. Bruynooghe, A. Eriksson, and G. Fulli, "Load following operating mode at nuclear power plants and incidence on operation and maintenance costs. Compatibility with wind power variability", EC, JRC Scientific and Technical Reports, Brussels, Belgium, 2010.

[9] A. Lokhov, "Technical and economic aspects of load following with nuclear power plants", NEA, OECD, Paris, France, Jun. 2011.

[10] A. M. Choho, "Major innovation in PWR load follow operations by AREVA", in Proc. 2013 Atoms for the Future Conf.

[11] H. Grard and J. B. Thomas, "The nuclear fleet: a decisive enabler to integrate a share of renewables (in the framework of a comprehensive systems solution)", in Proc. 2013 Atoms for the Future Conf.

[12] F. Wagner, "Feature of an electricity supply system based on variable input", Max Planck Institute of Plasma Physics, IPP 18-1, Sep. 2012.

[13] Ministère de l'Ecologie, du Développement Durable et de l'Energie, "Synthèse des travaux du débat national sur la transition énergétique de la France", Conseil National du Débat, Jul. 2013.

[14] ANCRE, "Scénarios de l'ANCRE pour la transition énergétique", 2013.

[15] ADEME, "L'exercice de prospective de l'ADEME : Vision 2030-2050", Jun. 2013.

[16] RTE, "Bilan électrique 2013", 2013.

[17] "Nucléaire: EDF détaille les coûts de son «grand carénage»", Les Echos, Fev. 21, 2014. [Online]. Available: www.lesechos.fr/entreprises-secteurs/energie-environnement/actu/0203331225826-nucleaire-edf-detaille-les-coutsde-son-grand-carenage-651911.php

[18] F. Ueckerdt, L. Hirth, G. Luderer, and O. Edenhofer, "System LCOE: What are the costs of variable renewables?", Energy, vol. 63, pp. 61-75, Dec. 2013.

[19] D. Connolly, H. Lund, B. V. Mathiesen, and M. Leahy, "Modelling the existing Irish energy-system to identify future energy costs and the maximum wind penetration feasible", Energy, vol. 35, pp. 2164-2173, Mar. 2010.

[20] M. Barnacle, E. Robertson, S. Galloway, J. Barton, and G. Ault, "Modelling generation and infrastructure requirements for transition pathways", Energ Policy, vol. 52, pp. 60-75, May 2012.

[21] RTE database. [Online]. Available: http://www.rte-france.com/fr/developpement-durable/eco2mix/telechargement-dedonnees

[22] M. S. Salvadores, J. H. Keppler, "Projected costs of generating electricity", Nuclear Energy Agency, OECD, Paris, France, 2010.

[23] Power Reactor Information System (PRIS) database, IAEA. [Online]. Available: http://www.iaea.org/pris/

[24] "Les coûts de la filière électronucléaire", Cour des comptes, Rapport public thématique, Paris, France, Jan. 2012. 
World Renewable Energy Congress - WREC XIII, 3-8 August 2014, University of Kingston, London, UK

[25] $\mathrm{CO}_{2}$ market website: http://www.pointcarbon.com [accessed: 27/02/14]

[26] M. F. Ruth, O. R. Zinaman, M. Antkowiak, R. D. Boardman, R. S. Cherry, and M. D. Bazilian, "Nuclear-renewable hybrid energy systems: opportunities, interconnections and needs", Energy Convers Manage. vol. 78, pp. 684-694, Feb. 2014. 